\section{Analysis of Kaolin Particle Film Use and Its Application on Coffee}

\author{
Shawn R. Steiman' ${ }^{1}$ and Harry C. Bittenbender \\ Department of Tropical Plant and Soil Sciences, University of Hawaii at \\ Manoa, 3190 Maile Way, St. John 102, Honolulu, HI 96822
}

Travis W. Idol

Department of Natural Resources and Environmental Management, University of Hawaii at Manoa, 1910 East-West Road, Honolulu, HI 96822

Additional index words. Surround WP, Coffea arabica, shade

\begin{abstract}
Application of a kaolin-based particle film, Surround WP, was analyzed using glass plates and slides. The kaolin was sprayed on coffee grown in full sun to evaluate physiological responses to this shading technique. Kaolin reduced photosynthetically active radiation and ultraviolet transmission and decreased surface temperatures on glass slides. In the second year of application, photosynthesis of plants sprayed with kaolin was $71 \%$ greater than full-sun plants and yields were doubled. Leaf temperature was significantly lower in the kaolin treatment, but stable $C$ isotope ratios, water use efficiency, nodal growth, and specific leaf area were not. The most likely mechanisms for increased yield are increased light transmittance to inner-canopy nodes or greater storage of photosynthate during the first year. Although results from this study suggest there is much promise for improving the performance and yield of coffee with kaolin application, studies with other species have shown inconsistent results. This inconsistency may be linked to variation in application techniques, kaolin coverage and subsequent effects on light transmission, leaf temperature, and physiological function. Thus, reports on physiological performance alone are insufficient to evaluate the use of kaolin application. Detailed information on application techniques combined with measurements of end-product criteria such as yield or quality are recommended to facilitate cross-study comparisons.
\end{abstract}

Systematic research with kaolin as a particle film technology began in 1970 (Abou-khaled et al., 1970). This report stimulated research that contributed to the formulation of Surround WP, a commercially available kaolin-based powder. This product is currently used to reduce pest and disease pressures, improve fruit appearance, and affect plant physiological responses (Glenn and Puterka, 2005).

Within a single plant species, physiological responses to kaolin particle film application such as photosynthetic rate and leaf temperature vary inconsistently (Gindaba and Wand, 2007). One possible explanation for this may be differences in application of the product. Most authors failed to calculate the amount of light transmitted through the kaolin, the amount of surface area covered, or even the amount of kaolin on a typical leaf. In addition, different application rates and

Received for publication 25 May 2007. Accepted for publication 30 July 2007 .

Funding for this project provided by USDATSTAR, grant award no. 2003-34135-14033. We thank the Hawaii Agriculture Research Center for use of their field site. We also thank Drs. Loren Gautz, Lauren Sack and Kent Kobayashi for use of equipment and advice on experimental design.

${ }^{1}$ To whom reprint requests should be addressed; e-mail steiman@hawaii.edu equipment are likely to contribute to differences in plant response.

This article explores the application of Surround WP using glass plates and slides and field-grown Coffea arabica L. 'Typica'. Coffee is a shade-tolerant plant that produces high yields in unshaded conditions. However, high rates of fertilization and irrigation are necessary to maintain such an output. The ecophysiological differences between sun and shaded coffee are well documented and the tradeoffs understood (Beer et al., 1998; Cannell, 1985; Da Matta, 2004). Kaolin appeals to producers.

Our objective was to determine the effect of different kaolin application rates on surface coverage, radiation transmission, and surface temperature of a glass substrate and how this translated into effects on the physiology of coffee leaves, a crop for which there are no previous reports of its use. Secondarily, we wanted to determine what information should be reported by researchers to maximize information transfer and facilitate new uses of this particle film technology.

\section{Materials and Methods}

Determination of photosynthetically active radiation and ultraviolet transmittance, surface temperature, particle density, and percentage of surface area covered. Glass offers a novel method for shading coffee that plates $(30 \times 62 \times 0.35 \mathrm{~cm})$ were sprayed zero to four times with Surround WP (BASF, Research Triangle Park, NC) at a concentration of $60 \mathrm{~g} \cdot \mathrm{L}^{-1}$ water under 345 to $415 \mathrm{kPa}$ of pressure $\left(\approx 500 \mathrm{~L} \cdot \mathrm{ha}^{-1}\right)$ with $0.5 \%$ Umbrella (Monterey AgResources, Fresno, CA) as an adhesive. Plates were sprayed using a $20-\mathrm{L}$ Field King backpack sprayer (The Fountainhead Group, New York Mills, NY) fitted with a Uni-Jet flathead, brass nozzle (model 8002).

The spray tip was $\approx 1.0 \mathrm{~m}$ from the plates. Before spraying, four preweighed microscope slides were placed on each plate. Four light measurements were taken by placing a LI-Cor LI-190SA quantum photosynthetically active radiation $(P A R)$ sensor (LI-COR Biosciences, Lincoln, NE) $3 \mathrm{~cm}$ beneath each glass plate. Light transmittance was measured by dividing the $P A R$ values for a sprayed plate by the average value of the unsprayed plate. The same method was used to measure ultraviolet transmittance (model UVM; range, 250 to $400 \mathrm{~nm}$; Spectrum Technologies, Plainfield, IL) and surface temperature (emissivity $=0.95$; model Raynger ST; Raytek, Santa Cruz, CA).

After spraying, the microscope slides were dried and reweighed to determine the amount of kaolin dispersed per unit area. The percentage of area on each microscope slide covered by kaolin was determined using an Epson scanner (Epson, Long Beach, CA) with a black background. Scanned images were imported into Adobe Photoshop Elements 2.0 (Adobe, San Jose, CA). The image color was contrasted to force all spots on the image to be defined as pure white. A luminosity reading was calculated by the software and converted into a frequency histogram that showed clear separation between the black background and the white spots. This was used as the measure of the percent area covered by the kaolin.

Field experiment. Coffea arabica L. 'Typica' trees growing in Kunia, Oahu Island, HI $\left(21^{\circ} 23^{\prime} \mathrm{N}, 158^{\circ} 2^{\prime} \mathrm{W}\right.$, elevation $=83 \mathrm{~m}$ asl $)$ were chosen for this experiment. The trees were planted in 1987 and are currently in $1 \times 5$ to 6 - $\mathrm{m}$ hedgerows (originally $1 \times 3 \mathrm{~m}$ ). The trees were stumped in Jan. 2004 to a height of $0.5 \mathrm{~m}$. Four orthotropic shoots were allowed to regrow on the stump. In June 2005, all shoots were decapitated above the highest lateral branch supporting fruit. All trees were drip-irrigated and fertigated equally.

Experimental units consisted of four consecutive trees. The two outer trees served as border trees and were not subject to data collection. Five rows in the field were selected as blocked replicates. Experimental units were randomly assigned to either an unshaded or kaolin treatment.

Trees in the kaolin treatment were sprayed semimonthly in the same manner as the glass plates. The spray nozzle was 0.4 to $1.0 \mathrm{~m}$ from the leaves. Spraying began on 24 Feb. 2005 and continued until 5 Dec. 2006.

As a test of kaolin coverage on coffee leaves, 14 preweighed microscope slides were attached to coffee leaves with adhesive putty. The trees were then sprayed as previously 
described and the microscope slides removed to estimate the amount of kaolin applied and the percent leaf coverage.

Physiological response to kaolin coverage. Leaf surface temperature, $\mathrm{C}$ isotope discrimination, $\mathrm{CO}_{2}$ assimilation, branch growth extension, and yield were measured on plants in the field. The most recently matured leaves (4 to 6 weeks old) on each branch were used.

Temperature measurements were taken between 1100 and 1200 HR on 4 May 2005 using a Mini IR Temp Meter (emissivity = 0.95 fixed; Spectrum Technologies). Six leaves per experimental unit from both sides of the row were measured.

Eight pairs of leaves were collected from each experimental unit between 0730 and 0830 HR on 13 Sept. 2005 and put in a chilled cooler. Leaf area was measured using a LICor 3100C leaf area meter (LI-COR Biosciences). The leaves were dried at $70{ }^{\circ} \mathrm{C}$ for $2 \mathrm{~d}$ and then weighed. Dried leaves were then ground using a Wiley mill (Thomas Scientific, Swedesboro, NJ). Carbon isotope compositions were determined using an online carbon-nitrogen analyzer coupled with an isotope ratio mass spectrometer (Finnigan ConFlo II/Delta-Plus, Bremen, Germany) at the University of Hawaii Stable Isotope Biogeochemistry Laboratories. Isotope values were reported in standard d-notation relative to an international standard. The standard for carbon was V-PDB and was corrected for the contribution of ${ }^{17} \mathrm{O}$ using the method of Santrock et al. (1985). A glycine standard was used to ensure accuracy of all isotope measurements.

Leaf $\mathrm{CO}_{2}$ assimilation $(A)$ measurements were taken with a CIRAS-1 portable photosynthesis system (PP Systems, Amesbury, MA) between 0900 and 1200 HR on 2 Aug. $2006\left(\mathrm{CO}_{2}\right.$ reference level $=375 \mathrm{ppm}$, settling time $\approx 2$ min). Measurements began with Block 1 and continued consecutively. Each block measurement lasted $\approx 20 \mathrm{~min}$. Ambient $P A R$ values for this time period ranged from 425 to $2200 \mu \mathrm{mol} \cdot \mathrm{m}^{-2} \cdot \mathrm{s}^{-1}$ quanta. Five leaves from each experimental unit each were measured once. Water use efficiency (WUE) was calculated by dividing $A$ by $g_{\mathrm{S}}\left(\mathrm{G}_{\mathrm{s}}\right)$.

On 9 Aug. 2006, 20 lateral branches were randomly selected per experimental unit. To estimate lateral growth, new fruitful nodes were counted on each branch. Fruitful nodes were defined as the number of fruiting nodes plus nodes with flower buds present.

Coffee was harvested for two consecutive seasons. Ripe cherries were harvested as necessary from 25 Aug. 2005 to 7 Feb. 2006 and 10 Aug. 2006 to 5 Dec. 2006. Cherries were processed to green bean and weighed.

Physiological data were compared using Student's $t$ test. All data were analyzed using JMP 5.0.1.2 statistical software (SAS Institute, Cary, NC).

\section{Results and Discussion}

The amount of kaolin sprayed ranged from 0.16 to $3.52 \mathrm{~g} \cdot \mathrm{m}^{-2}$ (Fig. 1). More kaolin was sprayed on slides during a single pass of the sprayer over the glass plates (first four closed circles) than on slides attached to coffee leaves (open circles). This likely occurred because leaves on trees are presented at different angles and distances from the sprayer.

$P A R$ passing through the glass plates was reduced by as much as $56 \%$ after addition of kaolin (497 to $217 \mu \mathrm{mol} \cdot \mathrm{m}^{-2} \cdot \mathrm{s}^{-1}$ quanta; Fig. 2). Ultraviolet radiation was reduced by $48 \%$ when the greatest kaolin density was on the glass plate $\left(47.5\right.$ to $24.9 \mu \mathrm{mol} \cdot \mathrm{m}^{-2} \cdot \mathrm{s}^{-1}$ quanta). The surface temperature of the glass plates decreased $\approx 10 \%\left(32.6\right.$ to $\left.29.4{ }^{\circ} \mathrm{C}\right)$.

Table 1 shows the physiological measurements of coffee in the field. Specific leaf area was similar between the sun and kaolinsprayed leaves. Leaf surface temperatures in the kaolin treatment were significantly lower by $3.4{ }^{\circ} \mathrm{C}$. Photosynthesis in kaolin leaves was significantly greater by $71 \%$ but WUE was not. Perhaps more importantly, net photosynthesis of sun leaves declined rapidly over time during the late morning, whereas kaolin-sprayed leaves continued to exhibit high rates of net photosynthesis (Fig. 3). Yield of sprayed trees was $14 \%$ and $99 \%$ higher than sun trees for the first and second years, respectively. This difference was significant during the second year.

Published data of kaolin density on a leaf or glass surface ranges from 0.85 to 10.0 $\mathrm{g} \cdot \mathrm{m}^{-2}$ with most values averaging 5 to $6 \mathrm{~g} \cdot \mathrm{m}^{-2}$ for label-recommended application rates (Glenn et al., 1999, 2001; Jifon and Syvertsen, 2003; Lombardini et al., 2005; Wünsche

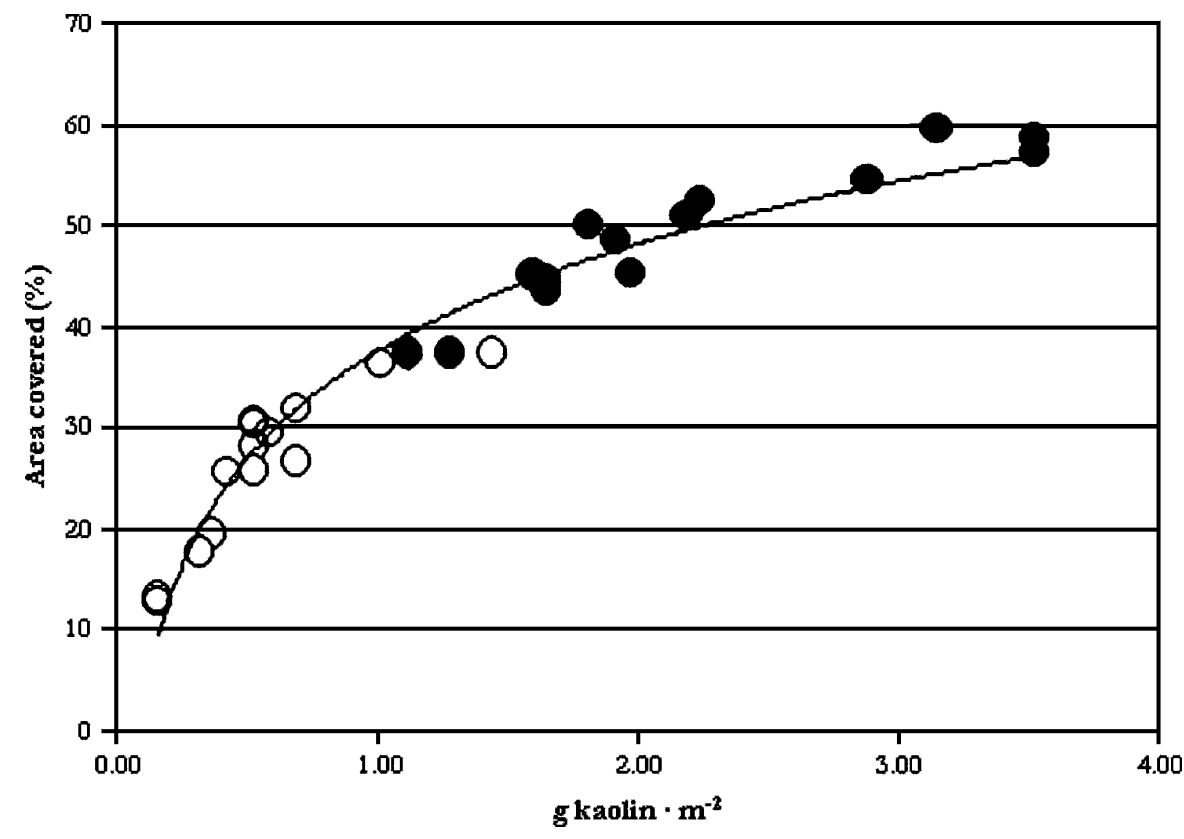

Fig. 1. Percentage of surface area covered versus kaolin density. Kaolin sprayed on coffee leaves $(\bigcirc)$; kaolin sprayed on glass slides $(\bullet)$. Coverage equation: $\mathrm{y}=15.37 \ln (\mathrm{x})+37.50, \mathrm{r}^{2}=0.96, P<0.0001$.

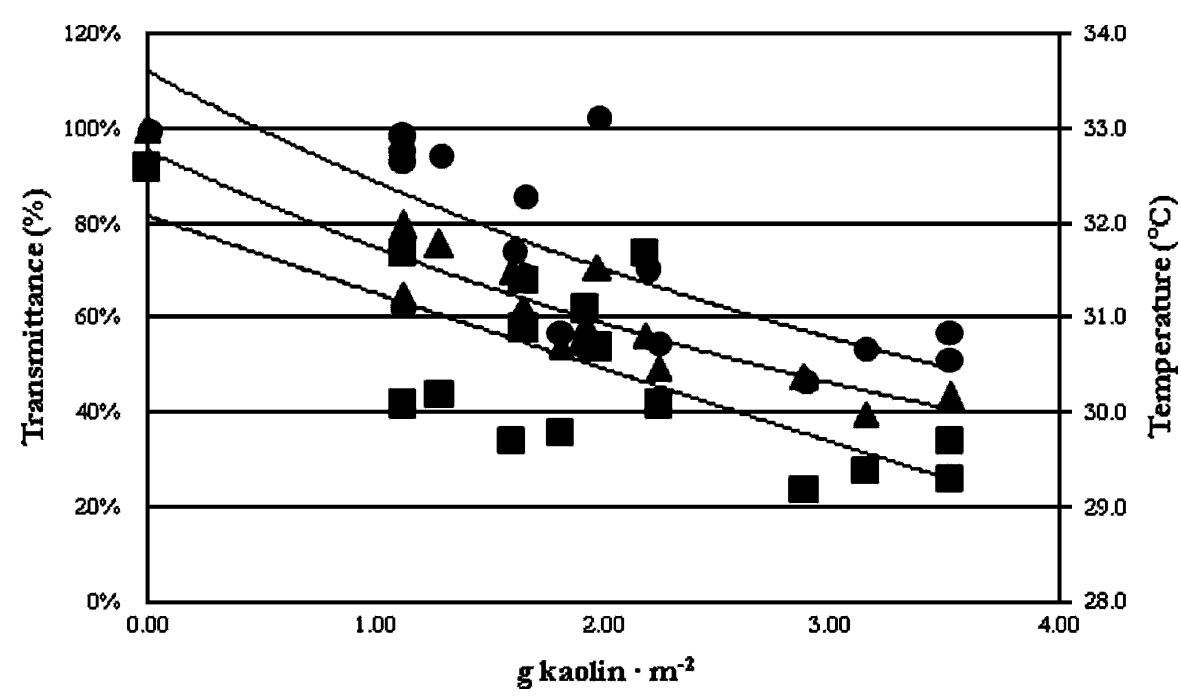

Fig. 2. Photosynthetically active radiation $(P A R)$, ultraviolet, and temperature response to kaolin density. Ultraviolet equation $(\bullet): \mathrm{y}=1.123 \mathrm{e}^{-0.233 x}, \mathrm{r}^{2}=0.62 ;$ PAR equation $(\mathbf{A}): \mathrm{y}=957 \mathrm{e}^{-0.241 x}, \mathrm{r}^{2}=0.85$; temperature equation $(\boldsymbol{\square})$ : $\mathrm{y}=32.072 \mathrm{e}^{-0.028 \mathrm{x}}, \mathrm{r}^{2}=0.53 . P<0.001$ for all equations. 
et al., 2004). The average density in the present study was $0.57 \mathrm{~g} \cdot \mathrm{m}^{-2}$, an order of magnitude lower than the published average. Even with four passes over the glass plates, the maximum kaolin density in the present study was less than $4 \mathrm{~g} \cdot \mathrm{m}^{-2}$.

The lower densities of kaolin in our study, however, reduced PAR transmission to the same extent as in previous work (Glenn et al., 1999; Jifon and Syvertsen, 2003). Previous studies attained $60 \%$ PAR transmittance at $\approx 10 \mathrm{~g} \cdot \mathrm{m}^{-2}$, whereas the same reduction in transmittance was attained with only $2 \mathrm{~g} \cdot \mathrm{m}^{-2}$ in the present study (Fig. 2). Although the data in the present study also show that ultraviolet transmission is reduced by kaolin, a direct comparison with work by Glenn et al. (2002) is difficult to make; their study measured reflection at individual wavelengths, not an average of wavelengths. Both studies demonstrate that increased kaolin coverage reduces ultraviolet transmission.

Researchers using kaolin generally have used the label recommendation rate of 30 to $60 \mathrm{~g} \cdot \mathrm{L}^{-1}$. Thus, the large discrepancy between kaolin densities between previous studies and the present one may be related to application or measurement differences. The logarithmic relationship between kaolin density and surface area covered (Fig. 1) suggests that repeated applications have a layering effect. Any factor affecting kaolin deposition and

Table 1. Physiological measurements on coffee plants.

\begin{tabular}{lccc}
\hline Trait & Kaolin & Sun & $\begin{array}{r}\text { Significant } \\
\text { at } P<0.05\end{array}$ \\
\hline Specific leaf area $\left(\mathrm{cm}^{2} \cdot \mathrm{g}^{-1}\right)$ & 133.4 & 136.3 & No \\
Leaf temp $\left({ }^{\circ} \mathrm{C}\right)$ & 33.7 & 37.1 & Yes \\
Nodes per branch & 13 & 12 & No \\
$A\left(\mu \mathrm{mol} \cdot \mathrm{m}^{-2} \cdot \mathrm{s}^{-1} \mathrm{CO}_{2}\right)$ & 14.2 & 8.3 & Yes \\
WUE $\left(\mathrm{A} \cdot \mathrm{G}_{\mathrm{s}}{ }^{-1}\right)$ & 0.44 & 0.12 & No \\
${ }^{13} \mathrm{C}(\%)$ & -25.3 & -25.9 & No \\
Yield $\left(\mathrm{kg} \cdot \mathrm{ha}^{-1}\right.$ green) & & 1381 & No \\
2005 & 1581 & 1520 & Yes \\
2006 & 3031 & &
\end{tabular}

$A=$ assimilation; WUE $=$ water use efficiency.

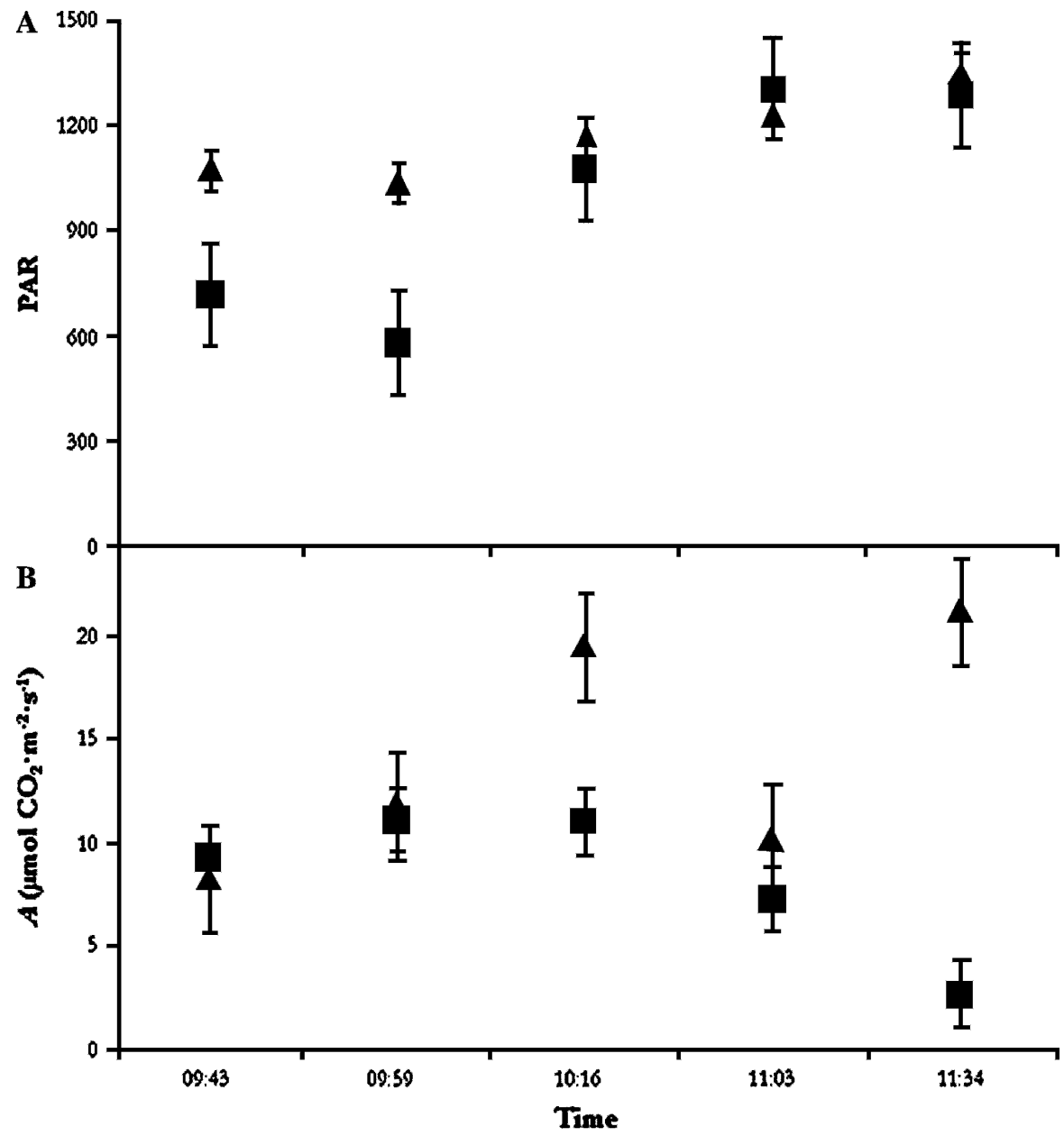

Fig. 3. Photosynthetically active radiation and $\mathrm{CO}_{2}$ assimilation over time. Times are an average of the timespan each block was measured. Data points are an average of five leaves from each experimental unit for sun $(\mathbf{\square})$ and kaolin $(\mathbf{A})$ treatments. Error bars represent $\pm 1 \mathrm{SE}$. layering will also influence light transmittance. These factors include spray solution adjuvant, the type of sprayer used (blast sprayer versus hand pump), pump pressure, particle size and shape of the nozzle, distance from the object sprayed, the speed of movement over the object, and the number of passes made. In addition, the type of light source and distance between the sprayed surface and the light sensor will also affect results.

Kaolin reduces surface temperatures (Glenn et al., 2002; Jifon and Syvertsen, 2003; Wünsche et al., 2004), although occasionally, no difference is found (Russo and Díaz-Pérez, 2005). Photosynthetic responses to kaolin generally show a decrease in carbon assimilation (Gindaba and Wand, 2007; Lombardini et al., 2005; Russo and DíazPérez, 2005, Wünsche et al., 2004); however, this is not always the case (Glenn et al., 2001; Jifon and Syvertsen, 2003).

The increased carbon assimilation of coffee leaves in the kaolin treatment is one of the largest observed with kaolin use. Carbon assimilation in coffee maximizes at 7 to $11 \mu \mathrm{mol} \cdot \mathrm{m}^{-2} \cdot \mathrm{s}^{-1} \mathrm{CO}_{2}$ and saturates at 300 to $600 \mu \mathrm{mol} \cdot \mathrm{m}^{-2} \cdot \mathrm{s}^{-1}$ quanta (Rena et al., 1994). Although the heavy fruit load on the kaolinsprayed trees may have contributed to the increased photosynthesis (Vaast et al., 2006), it can only account for a small percentage.

Differences in $A$ do not appear to be the result of increased water stress in the full-sun plants because plants were irrigated as needed, including on the day photosynthesis measurements were taken. Furthermore, there were no differences in WUE or the leaf-stable $\mathrm{C}$ isotope ratio. In coffee, little change, if any, occurs to stable $\mathrm{C}$ isotope ratios with moderate shading. Although stable $\mathrm{C}$ isotope values could have been confounded with leaf age and shading, Gutiérrez and Meinzer (1994) concluded that older, self-shaded coffee leaves of 'Red Catuai' had greater WUE than younger, sun leaves. With shading of 50\% using 'Yellow Catuai,' Carelli et al. (1999) found no differences in stable $\mathrm{C}$ isotope values, although differences were detected with $80 \%$ shade. In addition, Lombardini et al. (2005) found no affect of kaolin application on $\mathrm{C}$ isotope discrimination in pecan twigs.

Ambient PAR can reach 2000 $\mu \mathrm{mol} \cdot \mathrm{m}^{-2} \cdot \mathrm{s}^{-1}$ quanta in Kunia and photosynthesis in coffee leaves heavily declines above a leaf temperature of $35{ }^{\circ} \mathrm{C}$ (Rena et al., 1994). The increasing separation between the treatments later in the morning suggests that photosynthesis was shutting down in the full sun treatment but not in the kaolin treatment. Consequently, the smaller $A$ in the sun treatment was likely the result of prolonged exposure to higher than optimal temperatures or photoinhibition from high irradiance.

Well-tended coffee grown in full sun is expected to achieve the potential maximum yield for a tree. Because the kaolin application from the first season began after the first major flowering event, the kaolin could only have affected yield by altering fruit abortion, 
fruit drop, or bean size. Similar yields from both treatments suggest fruit abortion and fruit drop were not different. Average bean size was also similar (data not shown). In the second season, yields were doubled in the kaolin treatment. Because the trees were maintained at physiologically similar heights and had the same number of orthotropic shoots, fruitful nodes, and green bean size (data not shown), the component of yield affected is most likely fruits per node. A possible explanation for this response is an increase in light reflected from the kaolin to the more shaded inner canopy nodes that resulted in increased floral initiation. It is also possible that a greater amount of starch was stored during the first growing season as a result of light and temperature amelioration. This might have permitted greater floral initiation and/or fruit production the next year. Because lateral growth and specific leaf area were not different between treatments, any additional photosynthate was probably being partitioned to the developing fruits.

These data were collected as part of a larger shade coffee experiment and the positive yield response in the kaolin treatment was unexpected. Hence, the data presented are incomplete to fully describe the physiological explanation for the response to kaolin. Although most of the data are single point-intime measurements, the data consistently point to a clear difference between kaolintreated leaves and sun leaves. Further research is needed to elucidate this phenomenon.

Although several studies, including this one, have demonstrated the benefits of kaolin on various crop species, the inconsistencies in the data are discouraging. Comparing studies using different species and application techniques does not allow us to understand these responses to kaolin, especially if particle density and light transmittance through the kaolin are not equivalent. Consequently, comparing responses such as pho- tosynthetic rate and WUE between species, or even experiments, is meaningless unless all application factors can be controlled or accounted for.

Attempting to understand the underlying mechanism of any plant response is the motivation of this type of scientific inquiry and it is not discouraged. However, as a result of the current poor translation of kaolin effects between experiments, paramount to mechanistic data must be end-product criteria like plant growth, yield, or crop quality. Reports also should include kaolin coverage and effects on light transmittance, because these should have the largest effects on intercepted solar radiation and leaf temperature.

\section{Literature Cited}

Abou-khaled, A., R. Hagan, and D. Davenport. 1970. Effects of kaolinite as a reflective antitranspirant on leaf temperature, transpiration, photosynthesis, and water use efficiency. Water Resour. Res. 6:280-289.

Beer, J., R. Muschler, D. Kass, and E. Somarriba. 1998. Shade management in coffee and cacao plantations. Agrofor. Syst. 38:139-164.

Cannell, M. 1985. Physiology of the coffee crop, p. 108-134. In: M. Clifford and K. Willson (eds.). Coffee: Botany, biochemistry and production of beans and beverage Croom Helm, London.

Carelli, M., J. Fahl, P. Trivelin, and R. QueirozVoltan. 1999. Carbon isotope discrimination and gas exchange in Coffea species grown under different irradiance regimes. Rev. Bras. Fisiol. Veg. 11:63-68.

Da Matta, F. 2004. Ecophysiological constraints on the production of shaded and unshaded coffee: A review. Field Crops Res. 86:99-114.

Gindaba, J. and S. Wand. 2007. Climate-ameliorating measures influence photosynthetic gas exchange of apple leaves. Ann. Appl. Biol. 150:75-80.

Glenn, D., E. Prado, A. Erez, J. McFerson, and G. Puterka. 2002. A reflective, processed-kaolin particle film affects fruit temperature, radiation reflection, and solar injury in apple. J. Amer. Soc. Hort. Sci. 127:188-193.
Glenn, D. and D. Puterka. 2005. Particle films: A new technology for agriculture. Hort. Rev. (Amer. Soc. Hort. Sci.) 31:1-44.

Glenn, D., D. Puterka, S. Drake, T. Unruh, A. Knight, P. Baherle, E. Prado, and T. Baugher. 2001. Particle film application influences apple leaf physiology, fruit yield, and fruit quality. J. Amer. Soc. Hort. Sci. 126:175-181.

Glenn, D., G. Puterka, T. Vanderzwet, R. Byers, and C. Feldhake. 1999. Hydrophobic particle films: A new paradigm for suppression of arthropod pests and plant diseases. J. Econ. Ent. 92:759-771.

Gutiérrez, M. and F. Meinzer. 1994. Carbon isotope discrimination and photosynthetic gas exchange in coffee hedgerows during canopy development. Aust. J. Plant Physiol. 21:207219.

Jifon, J. and J. Syvertsen. 2003. Kaolin particle film applications can increase photosynthesis and water use efficiency of 'Ruby red' grapefruit leaves. J. Amer. Soc. Hort. Sci. 128:107112.

Lombardini, L., M. Harris, and D. Glenn. 2005. Effects of particle film application on leaf gas exchange, water relations, nut yield, and insect populations in mature pecan trees. HortScience 40:1376-1380.

Rena, A., R. Barros, M. Maestri, and M. Söndahl. 1994. Coffee, p. 101-122. In: B. Schaffer and P. Anderson (eds.). Handbook of environmental physiology of fruit crops, Vol II: Subtropical and tropical crops. CRC Press, Boca Raton, FL.

Russo, V. and J. Díaz-Pérez. 2005. Kaolin-based particle film has no effect on physiological measurements, disease incidence or yields in peppers. HortScience 40:98-101.

Santrock, J., S. Studley, and J. Hayes. 1985. Isotopic analyses based on the mass spectrum of carbon dioxide. Anal. Chem. 57:1444-1448.

Vaast, P., J. Angrand, N. Franck, J. Dauzat, and M. Génard. 2006. Fruit load and branch ringbarking affect carbon assimilation and photosynthesis of leaf and fruit of Coffea arabica in the field. Tree Phys. 25:753-760.

Wünsche, J., L. Lombardini, and D. Greer. 2004. 'Surround' particle film applications: Effects on whole canopy physiology of apple. Acta Hort. 636:565-571. 